\title{
A Message from the Journal of Vestibular Research
}

The Journal of Vestibular Research is pleased to publish the abstracts for the XXIX Barany Society Meeting, which is being held in Seoul, Korea. The Journal of Vestibular Research is dedicated to the publication of high-quality, original, peer-reviewed papers in the area of vestibular function and its disorders. IOS Press, the publisher of the Journal of Vestibular Research and this abstract book, has agreed to provide free electronic access to the abstracts via the IOS website, www.iospress.nl and the JVR website, www.jvr-web.org. We hope that you will take the opportunity to peruse the Journal of Vestibular Research either online or in your library, and that you will consider submitting manuscripts to the Journal.

Joseph M. Furman

Editor-in-Chief

\&

Susan L. Whitney

Associate Editor

Journal of Vestibular Research

www.jvr-web.org 